\title{
AFECTOS PARA UN CUERPO QUE A SÍ MISMO NO ES UTOPÍA DE LA MUJER DE SUBAMÉRICA
}

\footnotetext{
Jorge Luis Yangali Vargas. Profesor de literatura de la Universidad Nacional del Centro del Perú. Doctorando en Letras Modernas por la Universidad Iberoamericana, Ciudad de México.

E-mail.yanlivargas@hotmail.com
}

\section{Resumo}

No artigo, discuto a quarta seção, do livro de poemas Mujer de subamérica, de Flor de Maria Ayala Leonardi, para entender a relação entre imposição ideológica e resistência a partir da utopia do ser biológico.

\section{Resumen}

En el artículo analizo la cuarta sección, del poemario Mujer de subamérica de Flor de María Ayala Leonardi para comprender la relación entre imposición ideológica y resistencia desde la utopía del ser biológico.

El título de la cuarta sección del poemario Mujer de subamérica (1988) de la escritora peruana Flor de María Ayala Leonardi se titula "Bera Iznez". Nombre propio que en lengua vasca se traduce como "a sí misma no es". Dicha sección está subdividida en once poemas numerados mediante los cuales este singular personaje nos narra, $\mathrm{y}-$ por hacerlo a través de poemas - también nos canta, desde un "no principio" su pasaje o transformación de (no)ser una niña-mujer hasta la asunción de (no)ser una mujer-madre.

Si partimos desconociendo el significado del nombre de este personaje que da título a esta sección, Bera Iznez, éste sólo nos anticipa la narración de un sujeto particular, cuyo nombre no es común en la onomástica peruana; más aún, en la antroponimia de la región desde donde se le enuncia: la región central andina. En su contexto patronímico Bera Iznez es un nombre que intriga en una doble dimensión: su oculto significado, si es que lo tiene, y su seductora sonoridad.

Según como está estructurado el poemario "Bera Iznez" es la última parte y le sucede a la "Mujer de subamérica". Por lo tanto, en una lectura convencional del libro (entiéndase de la primera a la última página) se trata de una sección donde un nombre propio y extraño llega para nombrar a la mujer, a la Mujer de Subamérica. El nombre se instala tanto en el territorio como en el cuerpo de esta mujer. Lo particular de una mujer queda instalado en lo universal. No obstante, el rasgo de este nombre es ser enigmático. Pero al instalarse en la mujer de Subamérica se hace de un lugar. Ayala Leonardi estaría proponiendo hacer un lugar a un nuevo nombre, a un significante sin significado local, sin sentido local, un significante "extranjero" que sólo puede hacerse presente a través de la potencialidad enigmática de su nombre.

Este hacerle un lugar a un nombre propio "extranjero" está configurado por el absoluto de la época (Mariátegui, 1987, p. 19), es decir por el momento en el que son escritos los poemas que conforman dicho poemario: la penúltima década del siglo XX. Década que ha llamado poderosamente la atención de la academia peruana en estas primeras décadas del siglo XXI puesto que tiene que ver con la descripción e interpretación del contexto sociopolítico peruano de la llamada "guerra popular" (así formulada por el partido comunista Sendero Luminoso), o "conflicto armado interno" (definida de este modo por la Comisión de la Verdad y Reconciliación), o "tiempo del miedo" (descrito así por el sociólogo Nelson Manrique y reafirmado tanto por la cineasta Pamela Yates como por el historiador Peter Klarén) y al que nosotros denominamos "tiempo de sub( )versión". Es nuestro propósito 
analizar el modo como este nombre propio - y con él, el cuerpo extranjero de Bera Iznez es instalado como sub-versión frente a los dogmáticos discursos de agitación política.

\section{1) Motivaciones ideológicas para no ser a sí misma.}

De acuerdo al crítico literario norteamericano Kenneth Burke toda la cultura y con ella la literatura está articulada por las acciones humanas, las mismas que por el carácter simbólico del lenguaje son motivadas. Esta asociación entre acciones y símbolos lleva a Burke a definir al hombre como un "animal que usa símbolos" (Burke, 1966, p. 4). Definición que distingue dos rasgos diferenciados y complementarios de lo humano: lo animal y lo simbólico. Desde esta perspectiva el hombre sería el único ser que en su relación o interacción con la realidad, a la que aprehende y conoce, emplea símbolos. La facultad de emplear símbolos constituye la ruptura del hombre frente al animal en el proceso evolutivo.

De acuerdo a Burke se tienen dos dimensiones en los que el hombre se ve como ser que evoluciona: la positiva, que guarda una estrecha correspondencia con la dimensión de la cosa o realidad tal cual, y la negativa que tiene que ver con el lenguaje. La dimensión visible es positiva. Aunque no es verbal; por la percepción humana de las cosas no carece de lenguaje. La dimensión negativa es propiamente la simbólica, es decir, aquella que se entiende desde lo verbal y por ende desde lo racional. Burke, de este modo, contrasta la negatividad del lenguaje con la positividad de la naturaleza o realidad tal cual.

En el proceso de simbolización el hombre establece jerarquías, muchas de ellas dicotómicas como alto y bajo, bello y feo, bueno y malo, varón y mujer, etc. Esta jerarquización es resultado de la negatividad del lenguaje puesto que al racionalizar la positividad de la realidad o del ser biológico se es consciente de la posibilidad del no ser o de la muerte. Esta conciencia de la muerte nos conduce a la negatividad en el proceso de simbolización; lo cual nos permite, al mismo tiempo, identificar y ser conscientes de la positividad de la fisicalidad.

A diferencia del animal el hombre no solo aprehende su realidad; también incorpora o sistematiza sus aprendizajes. Mediante el lenguaje el hombre produce saber y lo hace juzgando a partir de las jerarquías que están incorporadas al lenguaje. Esta producción de saber que ejecuta el hombre es fundamental en la propuesta de Burke. Pues en su enfoque el hombre no solo realiza movimientos sino que ejecuta acciones y con ellos pone en evidencia sus saberes.

Acciones de las que el hombre no puede sustraerse. Entendemos entonces que las acciones, están ontológicamente asociadas a la facultad del hombre de producirlas, emplearlas y replantearlas articulándolas en símbolos. No obstante, el hombre tampoco puede sustraerse a su animalidad. Animalidad que distinguimos de fisicalidad. Mientras la fisicalidad es guiada por movimientos no motivados, tanto la animalidad como la simbolicidad humana están orientadas por las motivaciones.

En el primer poema que narra y canta la vida de Bera Iznez el principio que es de pura positividad de la vida se ve alterada por la negatividad del lenguaje.

$$
\begin{aligned}
& \text { Apenas mi vida } \\
& \text { anidaba en su carne } \\
& \text { cuando los pájaros } \\
& \text { de mal agüero } \\
& \text { le dijeron } \\
& \text { "será mujer." }
\end{aligned}
$$


La vida de Bera Iznez se inicia desde el momento en que se anuncia su concepción y es pura positividad. Pero, fatídicamente, como la enunciación pasa por el lenguaje éste impone una categoría simbólica específica para dicha fisicalidad y por tanto la negativiza: "será mujer".

De este modo Ayala Leonardi se instala con Bera Iznez en la polémica biopolítica que busca responder a la interrogante sobre el momento en el que surge el binomio madreniño(a). Según los versos de Bera Iznez éste acontecimiento se da en el momento de la anidación intersubjetiva de la "carne"; vale decirse, en el momento de la anunciación. El momento en el que a una mujer su cuerpo le anuncia la presencia de otro cuerpo, de un potencial sujeto que es pura positividad biológica. Sin embargo llega el instante de "los pájaros/ de mal agüero" que anuncian la presencia de una "carne" que no solo tiene que ser cuidada sino que tiene la impronta fatídica de ser mujer. El sujeto que surge de la enunciación es un ser biológico pero al mismo tiempo, en el poema, es subjetivamente sexuado desde la negatividad del lenguaje. Los mecanismos como se reciben el mensaje que deviene con la enunciación tienen que ver con la administración política del mensaje y, por ende, de la "carne". Insistimos: la enunciación física y animal es pura positividad; mientras que la traducción de esta enunciación a los parámetros del lenguaje hacen que la recepción del mensaje se transforme en absoluta negatividad. Bera Iznez está estigmatizada por su sexo desde el (no) principio.

Siguiendo a Burke, entendemos que la animalidad del hombre, a diferencia de la de las otras especies, es motivada. La animalidad en el hombre actúa sobre su físico: el hombre simboliza su paso por el mundo físico, su moverse en el mundo. Al simbolizar sus movimientos o desplazamientos el hombre los transforma en acciones. Mientras que el movimiento propio de la fisicalidad es caótico (rizomático, dirían Deleuzze y Guatari). La acción humana es dirigida, motivada y actuada. La motivación que viene desde la animalidad se refiere a la satisfacción de las necesidades básicas. Los motivos que llevan al hombre al proceso de simbolización aluden a complejos y sofisticados propósitos o fines.

Esta facultad del hombre de direccionar o conducir sus acciones afectan primeramente su cuerpo y ejercen sobre él un poder o una fuerza. Una fuerza que asociada al logos (o símbolo) se constituyen en una fuerza de ley (Jaques Derrida, Giorgio Agamben), que toma la forma de un cuerpo-otro autónomo y ligado. Un cuerpo sociojurídico e ideológico que le permite al hombre en sociedad controlar (ser controlado), dirigir (ser dirigido) y simbolizar (ser simbolizado) tanto en su fisicalidad como en su animalidad.

Como leemos en los versos citados del primer poema la fisicalidad o la "carne" de Bera Iznez ha sido animalizada, humanizada y subjetivizada mediante un mensaje que contiene y, por ende, oculta su potencia física: "será mujer". Este ser concebido y anunciado es nombrado, clasificado y jerarquizado por el lenguaje, desde la negatividad.

Al ser, la carne de la próxima a nacer, contenida por lo simbólico, se la inserta en el mercado de jerarquías y valores, donde algunas carnes-mensajes valen más que otras. La suya, la carne-mensaje de Bera Iznez, está determinada por el desvalor que motiva el deseo de eliminarla. Pero los que representan dicho deseo, su madre o su padre, no tienen el "poder" (Ayala, 1998, p. 59, v.9) para hacerlo; por lo que les queda darle a esta carnemensaje el valor que merece lo devaluado: la ignorante indiferencia. 
En este sentido resulta importante que Bera Iznez no señale que los receptores de la enunciación de su cuerpo y al mismo tiempo sus representantes ante la sociedad no hayan tenido el "valor" para deshacerse de ella; pues llevaría la polémica al terreno axiológico y moral. Al decir: "y no poder deshacerse de mí" (Ayala, 1998, p. 59, v. 9) elige el término "poder" orientando el debate hacia el terreno político. Esto le permitirá, como lo veremos más adelante, apropiarse de la palabra que engloba lo político, al decir que descubrió su palabra: PODER.

De este modo la fuerza de contención de la ley o del símbolo sobre la animalidad del hombre tiene que ver con la condición y naturaleza política del mismo. El cuerpo humano es político. Burke al hablar de esta fuerza de contención del símbolo la denomina como ideología, la misma que es entendida como un sistema simbólico que moldea, direcciona y contiene (sujeta) las acciones del cuerpo. En otras palabras, la ideología motiva la animalidad del hombre. No obstante, cuando esta motivación ideológica o instrumento externo de motivación ya no tiene efectos en el cuerpo, el mismo cuerpo (social o individual) produce un instrumento alternativo igualmente motivante: la utopía.

Si el cuerpo humano no produjese utopía la condición humana del hombre estaría condenada al uso opresivo del poder y no se advertiría su rol desencadente (de romper cadenas). En este punto sería vago y ocioso precisar cuál de los instrumentos o motivaciones surge primero: utopía o ideología. Más provechoso resulta entender que ambos instrumentos motivan las acciones humanas y que dicho carácter motivacional del símbolo es el retorno consciente al cuerpo o a la fisicalidad.

Cuando olvidamos que la utopía es una acción simbólica se convierte en ideología totalitaria y conservadora. Cuando la utopía manifiesta modos concretos de realización o ejecución de acciones humanas se transforma en ideología. La ideología se extrema cuando se convierte en un "debo" alejándose de la motivación primera o primaria, es decir del "puedo", del "poder" que reclama para sí Bera Iznez.

\section{2) Contener el cuerpo desde la ideología}

A Bera Iznez desde el funesto presagio de su concepción se la circunscribe a una comunidad simbólica y al hacerlo se le impone una ideología que debe obedecer. Esta comunidad tiene mecanismos o instituciones a través de los cuales la ideología se impone. Se impone porque uno, en principio, no la elige y se impone sobre ella porque va más allá de ella misma, de sus habilidades y de sus sueños; de ahí el sentido de su nombre: ella, Bera, la mujer que a sí misma no es.

La ideología se le impone a través de diversos institutos ideológicos como la familia y el internado, los que operan en el terreno pedagógico de las acciones. El quinto poema es ilustrativo del modo como la ideología además de ideas abarca las prácticas, las acciones:

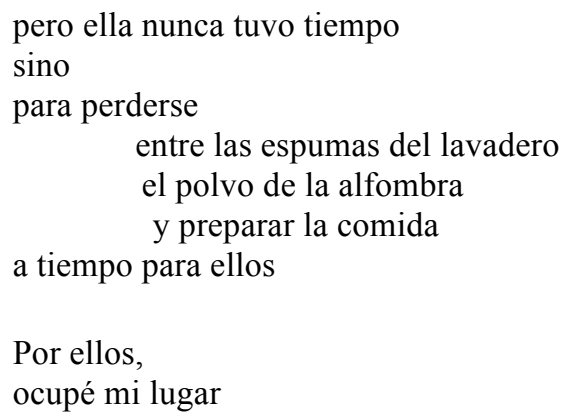


junto a la escoba,

el detergente

y las ollas. (Ayala, 1998, p. 63, vv. 3-14)

El dominio e imposición de la ideología de los "ellos" sobre la mujer, en este poema, es instalado y afirmado desde la práctica de la madre (Véase también, en el anexo, el segundo poema). Esta mujer, la madre, no necesitó instruir o alfabetizar (o su alfabetización no pasó por la letra pero sí por las acciones) a Bera Iznez en la ideología que las dominaba, que las contenía. A la madre de Bera le bastaba "perderse" en la práctica del debo para con los otros, para con los "ellos".

Estos "ellos" no incluyen a Bera Iznez. Cabe resaltar que, en el poema, la enunciadora es ella (nótese la tercera persona gramatical) quien al delimitar su "debo" en el territorio doméstico se distancia y diferencia de los "ellos". Pero no se crea que su exclusión de la mesa de los "ellos" al no ser servida y atendida por su madre es una autoexclusión. Sino que debe ser entendido como el resultado de una ideología que se impone, que es totalitaria en el control o negociación política de las acciones donde no hay lugar para la reflexión, donde las motivaciones tienden a repetir hereditariamente condiciones de exclusión. Donde el universo ideológico no da lugar al sub-verso utópico.

Estas motivaciones, según Burke, están vinculadas con el lenguaje, al que se le atribuye un rasgo sustancial: su performatividad (nótese el "ocupé mí lugar" del poema), es decir a su capacidad de accionar, su capacidad de originar y en otro momento de dejarse llevar por las motivaciones. A través de esta performatividad el lenguaje construye modos de comprender, conocer y sujetar lo real y la realidad (en términos de Burke hablamos de animalidad y fisicalidad). Ésta sujeción del sujeto se produce en el uso y comprensión de las dos dimensiones del lenguaje: el general o el de las acciones humanas y el de los términos particulares. Estos últimos permiten que la comprensión sea filtrada por un finito número de términos que en el lenguaje burkiano se denominan "terministic screens" (Burke, 1966, p. 44).

Por definición los "terministic screens" son aquellas "pequeñas partes de realidad" (Burke, 1966, p. 5) que experimentamos y aprehendemos y sirven de filtros o pantallas. Estos "términos pantalla" se originan y remontan al lenguaje general y son entre muchos: el antropológico, el sociológico, el psicoanalítico, el económico, el estético, el poético, etc. Al hacerse particular el lenguaje restringe su lente de análisis y comprensión y sólo puede percibir lo real y la realidad desde un aspecto, desde un encuadre, desde un enfoque.

Según Burke, el lenguaje particular o lente determinista al no poder independizarse de su procedencia u origen, es decir de ese conjunto de acciones simbólicas generales, si bien los limita - pone "término" - también los trasluce y representa. De ahí que, por ejemplo, cuando nos acercamos a un poema nos acercamos a lo que éste dice pero también a aquello que éste trasluce del lenguaje general.

En el sistema simbólico los "terministic screens" surgen o bien desde la ideología o bien desde la utopía. Utopía e ideología son soportados por los lenguajes disciplinares señalados líneas arriba. Por esta razón quisiéramos conocer desde donde emergen los términos del último poema de Bera Iznez. Poema donde encontramos un nuevo lenguaje, distinto de los otros diez poemas; es un lenguaje onírico donde abundan los términos asociados a la naturaleza y zoología:

Ya nada es tuyo 


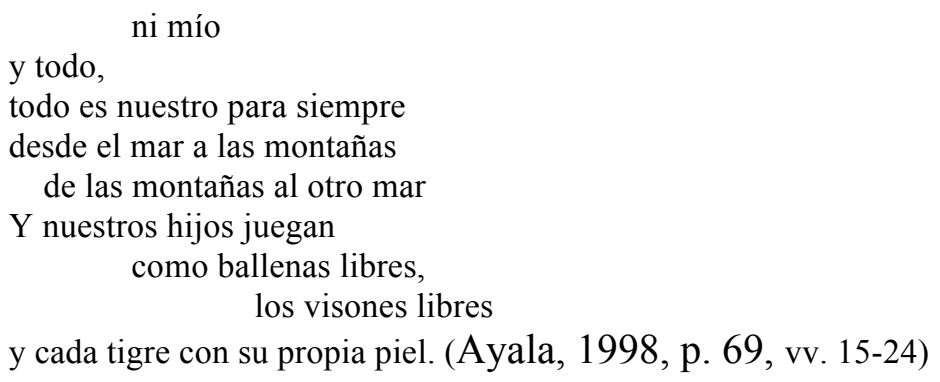

Es importante aquí como los "términos" naturales y zoológicos acrecientan la intención de Bera Iznez. La vida de ella da un vuelco que va de la ideología a la utopía; desde el debo al puedo. Aunque al momento de expresar su utopía de ser autónomo y por tanto un singular que anticipa su futura experiencia, ella habla desde y para sus "hijos".

A partir del verso 21 del undécimo poema el lenguaje de Bera Iznez no encuentra referentes humanos (abstractos o concretos) para describir su utopía por lo que se vale de la jerga zoológica. Su vuelco a lo animal no doméstico tiene que ver con el hecho de entender la libertad desde lo salvaje (ballenas y visones) y lo autónomo (tigre).

\section{3) Educada para (no) ser violada}

Burke siguiendo a Aristóteles distingue entre aquellos términos que tienen que ver con el lenguaje cientificista y los del "dramatistico". Mientras que los primeros siguen el camino de la nomenclatura y las definiciones los segundos entienden el lenguaje como un aspecto de la acción simbólica. El primero responde a la interrogante de si se es o no se es ("is, or is not" (Burke, 1966, p. 44)), mientras que lo "dramatistico" prescribe si se será o no ("thou shalt or thou shalt not" (Burke, 1966, p. 44)). Es decir, de acuerdo a Burke, el "dramatistic screen", por su carácter posible sería una pantalla determinista de lo general, de la potencialidad más que de la normatividad.

Visto de este modo, el epígrafe de la sección de Bera Iznez, por estar entrecomillado, recogería de un modo más literal y directo la voz de Bera a diferencia de la voz metafórica que de ella traslucen los otros once poemas. Esta voz directa orienta la lectura desde la afectividad.

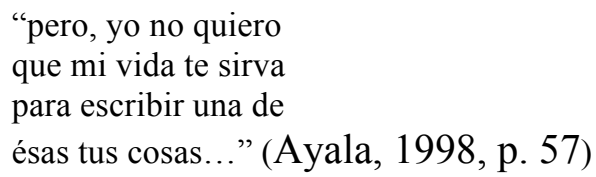

Bera, con este hablar directo da la bienvenida al lector y proporciona la llave para entrar a los poemas de esta sección condicionando la lectura y reflexión de la misma. Bera Iznez exige que sus poemas no se lean desde el deseo de reescribirlos; sino desde el poder sentirlos y sentirse afectado por ellos.

Ella quiere dejarse de ver a sí misma a través de la mirada que le impuso un rasgo inmutable: ser mujer. Los poemas nos muestran la lucha, por el poder, de esta mujer contra el estigma de su enunciación. Ella está luchando con las pantallas deterministas, incluso la poética, que se le ha dado para verse, con las formas de mujer construidas. Y procura hallar el filtro con los que puede hallarse a lo que a sí misma no es. Ella, la que no es la que creen(mos) que es nos está diciendo: yo no soy lo que mi mamá quiso transmitirme, 
tampoco soy lo que mi entorno quiso hacer de mí. Pues para ella su vida y su canto no tiene principio definido sino potencial. En otras palabras, la concepción misma de la mujer y del poema son potencia posible.

En El segundo sexo Simone de Beauvoir critica una antigua concepción en la cual la mujer era entendida y condicionada biopolíticamente desde el útero:

Lo que define de una manera singular la situación de la mujer es que, siendo como todo ser humano una libertad autónoma, se descubre y se elige en un mundo donde los hombres le imponen que se asuma como lo Otro: se pretende fijarla en objeto y consagrarla a la inmanencia, ya que su trascendencia será perpetuamente trascendida por otra conciencia esencial y soberana. $(1989$, p. 12)

En el recorrido de su crítica a esta postura, Beauvoir demuestra que hay mujeres que tienen útero pero que por algunas acciones que ellas realizan, la sociedad considera que éstas "no son mujeres". De modo que lo femenino en ella o él (a éste lo incluimos nosotros), no está condicionado por lo biológico. Lo que condiciona y constituye a un ser humano hembra como mujer es un imperativo social, un mandato, que Beauvoir recoge con los siguientes términos: "Sed mujeres, seguid siendo mujeres, convertíos en mujeres" (1989, p. 2). Este mandato lo podemos observar en la formación que Bera Iznez recibió tanto en su familia como en la escuela. Desde su concepción enunciante Bera además de ser ignorada en sus potencialidades recibió en su entorno familiar una formación que condicionó la imagen de mujer que la sociedad exigía de ella:



La familia y el entorno social de Bera al no reconocer y elogiar la demostración de su superioridad en destrezas atribuidas como exclusivas del género masculino, como el jugar al trompo o a "las batallas" fortalecen el imperativo que se le exige: ser mujer. Esto nos lleva a pensar que por más que ella, la mujer, identifique su "superioridad" mientras estos rasgos del sujeto singular no alcancen la aprobación social y simbólica siguen siendo la de una niña y una mujer que "no pued[e] reemplazar la imagen/ ni la creciente debilidad de [su] carne flaca." (Ayala, 1998, p. 61, poema 3, vv. 9-11) Y por lo tanto el imperativo ideológico prevalece.

Pero este imperativo no solo es familiar sino que se refuerza en otro ámbito igualmente comprometido en la formación de la identidad: la escuela, que en los cantos de Bera Iznez abarcan tres poemas (quinto, sexto y séptimo). La escuela de Bera es un internado regentado por una orden religiosa donde ella aprende el poder de atracción y provocación que tiene su marca física que le da identidad: su sexo. Sexo que provoca el deseo de aquellas que aún teniendo "útero" igual que ella son "no mujeres" y al mismo tiempo no son machos.

Bera en su entorno familiar, al sobrevivir a la intención o deseo de aborto de sus padres, a la indiferencia emocional, al maltrato físico de su padre y al asumir las tareas tradicionales atribuidas a su género, no había llegado a comprender el carácter retórico del 
deseo pero sí el poder simbólico de su carne. Por ello asume como armas de resistencia ante el embate retórico y físico de sus congéneres su organicidad misma (véase el poema 7).

Sobre el desarrollo sexual de la mujer Beauvoir recoge los estudios fisiológicos y psicoanalíticos de su tiempo entre los que destaca la teoría de la castración de la mujer: Mientras que en el hombre lo erótico se concentra en el pene en la mujer su madurez sexual tiene que ver con lo clitorial y lo vaginal. Muchas mujeres no alcanzan la madures vaginal lo que puede hacerlas frígidas u orientar su sexualidad hacia la homosexualidad. (Beauvoir 1989, p. 19). No obstante, esta postura fundamentaría la inferioridad sexual (biológica) de la mujer por lo que Beauvoir la rechaza y sostiene, más bien, que la inferioridad de la mujer no se debe a la ausencia de pene y consecuente rechazo de su feminidad:

[...] sino todo el conjunto de la situación; la niña no envidia el falo más que como símbolo de los privilegios concedidos a los muchachos; el lugar que ocupa el padre en el seno de la familia, la universal preponderancia de los varones, la educación, todo la confirma en la idea de la superioridad masculina.(1989, p. 20)

Toda vez que el falo tiene que ver con la simbolización de la soberanía en otros dominios además del sexual la mujer, según Beauvoir, se afirma como sujeto que intenta “equivalentes del falo" (1989, p. 22). Esto nos permite entender la resistencia de Bera en su confrontación con las mujeres-falos (incompletos ontológicamente) desde su radicalidad biológica, es decir desde su ser no fálico. En otras palabras, Bera se reconoce como mujer, pero no como la imagen de mujer que instituyó el sistema en ella, sino como mujer sexuada, como ser biológicamente potente cuyo sexo es deseado, para ser violado. Este tipo de deseo Bera no lo comprendía (vénase los versos finales del cuarto poema) sino hasta enfrentarse a sus compañeras-falo.

Al asumir su fisicalidad ella es consciente que los caminos del deseo se concretan en el cuerpo, en su cuerpo. Y todo deseo que se concreta lo hace en el cuerpo, al que atenta, al que viola. Bera Iznez lo entiende así, lo experimenta así. De ahí que su resistencia física efectiva en el internado, deja de serlo fuera del seno familiar y amical. En el octavo poema Bera es violentada por una multitud de "brazos" y "bocas" que la señalaron y vestidos con la noche: "saltaron las puertas/ costuras y/ botones." (Ayala, 1998, p. 66, vv. 8-10)

Este romper la resistencia no nos debe llevar a pensar en la ineficacia de la fe material (biológica) de Bera; sino en la dimensión de la fuerza que la violenta; puesto que esta no es una fuerza individual como el de las mujeres-falo sino una fuerza potencialmente ideológica como denota la metaforización del acto. Se trata de una animalidad multiplicada, bestial. De un acto violento que no puede ser contenido por la ley. Solo pudo haber sido confrontado por la suma de otras fuerzas, las que llegaron "demasiado tarde", sólo podía ser confrontado por la utopía que no llegó a tiempo. Este acto violento nos habla de una violencia de tránsito, de un rito de pasaje, de un acto que lleva al sujeto a transitar de un nivel a otro, de un estado a otro; de asumir la decisión de dejarse someter por la ideología o de dejar que despierte la utopía. Rito que está ilustrado por el "después" del noveno poema. Un acto violento que le otorga a Bera razones, impregnadas en su carne, para hablar desde su carne violentada y no caer en la retórica de hablar de la violencia sin haberla experimentado.

\section{4) Afectos para mi ser que no es}


Julia Kristeva (citada por Toril Moi) distingue tres tipos o formas de lucha feminista: en la primera, las mujeres reivindican la igualdad de acceso al orden simbólico que sería representado por el feminismo liberal, siendo el principio guía el de la igualdad. En la segunda se rechaza el orden simbólico de lo masculino en nombre de la diferencia sexual. Este modo de lucha estaría representado por el feminismo radical que busca la exaltación de la feminidad. La última forma de lucha tiene que ver con la negación de la dicotomía metafísica entre lo masculino y lo femenino. Esta destruye la oposición entre la masculinidad y la feminidad y por tanto pone en duda la misma noción de identidad. (Moi, 1988, p. 26) Lo que acontece en una posición política deconstruccionista como ésta última es que se reconoce que la naturaleza andrógina y con ella de toda dicotomía metafísica es "engañosa". (Moi, 1988, p. 27) En esta última modalidad de lucha se orienta la deconstrucción de categorías identitarias del género, que Judith Butler radicalizó señalando el carácter performativo no solo del género sino también de la sexualidad.

Derivados de estos modos de lucha Moi nos habla de dos formas de androginia: la platónica que apostaría por la unidad, y la deconstruccionista que alude al corte sin corte, al corte no en la realidad sino en lo real. Para el discurso sexista a diferencia del andrógino todo es separación. Es decir, un corte tanto genético como simbólico. Mientras que si seguimos la postura andrógina deconstruccionista entendemos que las categorías de género y sexualidad no son, sino que han devenido. Es decir el acontecimiento precede al ser-saber, o a la verdad como diría Alain Badiou. Si nos apoyamos en la clasificación de la lucha feminista hecha por Kristeva y Moi la lucha de Bera Iznez se asemeja a la lucha por la androginia deconstruccionista.

Cuando Bera Iznez lleva su lucha al terreno político al hacer suya la palabra (PODER), no hace de ésta exclusiva de su género; puesto que sostenida en otros "terministic screen", principalmente el sociológico, observa que el poder ha sido dicotómicamente distribuido en "inconsistentes" principios morales. Leamos el décimo poema:

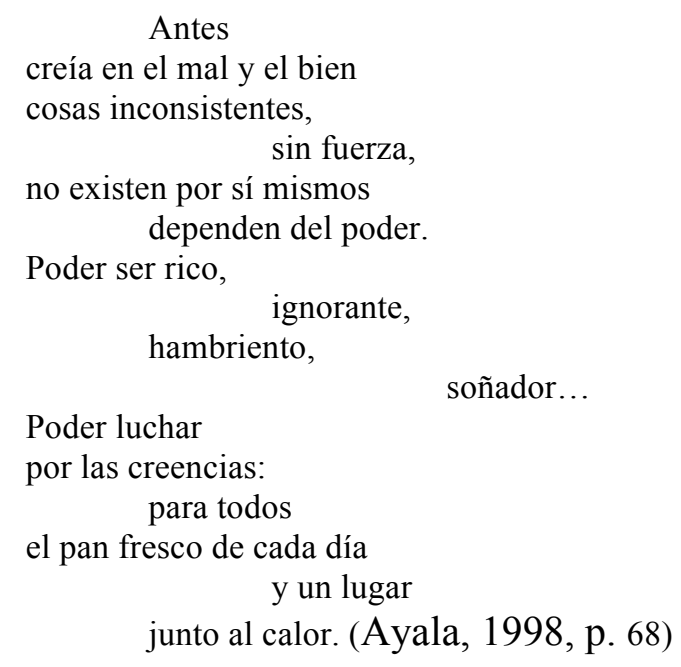

En la primera estrofa Bera Iznez no orienta su lucha por el terreno moral; pues ésta además de afirmar las dicotomías de exclusión mantiene oculta su dependencia de una fuerza originaria mayor: el poder. En Bera Iznez el poder lo es todo y su distribución y apropiación fractura la sociedad dividiendo a los individuos según sus "potencias" que son 
diferentes de unos y otros: "poder ser rico", "[poder ser] ignorante", "[poder ser] hambriento" y "[poder ser] soñador". En esta división social causada por el poder encontramos sujetos que están privados o favorecidos en lo económico, educativo, nutricional y espiritual (psicológico).

Ante este reconocimiento de la distribución del poder Bera Iznez orienta su lucha hacia el terreno de las utopías, de los sueños, de las "creencias", de la fe para todos; por "el pan fresco de cada día". Al conducir su lucha por el terreno de la fe política, se acerca a las luchas de otras feministas como las sufragistas y las representantes de las minorías sociales que orientaron su lucha por el terreno político-jurídico. ¿Cuál es el propósito de Bera Iznez de conducir su lucha por el terreno de la fe política?

Primero entendamos una diferencia que Bera Iznez establece entre religión y fe (“creencias" y "sueños"). El primero está limitado por sus propios térministics screens, los cuales han huido de la vida de Bera puesto que en su violento pasaje por la pedagogía de la violencia social no le sirvieron como armas de resistencia. De este modo, en el séptimo poema, afirma "extenuadas/ huyeron Obediencia/Pobreza y/ Castidad,/ recogiendo apresuradas/ sus inútiles ropajes." (Ayala, 1998, p. 65, vv. 23-28). Pero sus "uñas" y "dientes" si sirvieron como armas de resistencia y lucha. De ahí que la fe política para Bera Iznez tiene que ser entendida desde la materialidad de su "carne flaca", desde el poder de su inmanencia misma, desde su cuerpo que para feministas como Simone de Beauvoir, tienen postergada a la mujer; de ahí que la pensadora francesa abogue por la trascendencia, mientras que Bera lo hace desde la potencia de su ser biológico.

La psicología del desarrollo (según Moi) sostiene que el cerebro va aprendiendo cosas. Todas las cosas que uno ve los aprendemos mediante el lenguaje, el cual se vuelve más metafórico o simbólico; de ahí que construyamos una narrativa de vida que ya no es nuestra. La trascendencia de la simbolicidad nos aliena para creer y aspirar que es posible dejar de ser animales. Lo que hace Bera Iznez es volver a esa materialidad primigenia, a las acciones simbólicas de lucha con uñas y dientes, para construir desde allí su lucha por la creencia para todos, por su fe en la potencialidad de obtener para todos: "el pan fresco de cada día/ y un lugar/ junto al calor."

Cuando Burke hablaba de las pantallas cientificista y dramatista reconocía que el poeta también construye con sus "términos", filtros de realidad. En ese sentido podemos entender que cada artefacto artístico es un filtro, por lo tanto la poesía en particular y el arte en general tiene el mismo peso que la lengua cientificista u objetiva. La objetividad (ángulo u objetivo del lente) del arte es diferente de la objetividad de la ciencia. Como Aristóteles también reconocía y diferenciaba: "el uno [la historia y con ella la ciencia] dice las cosas tal como pasaron y el otro [la poesía] cual ojalá hubiera pasado" $(1988$, p. 14). Con el estagirita reconocemos que la poesía habla desde la utopía, desde la posibilidad. De ahí que Bera Iznez hable en su lucha: de "creencias", de fe política. Por lo tanto para poetas como Ayala Leonardi el cambio social que se buscaba en las últimas décadas del siglo XX no estaba del lado de la aplicación del dogma - del dogma ideológico social-comunista que caracterizó a los partidos políticos insurgentes como Sendero Luminoso y el Movimiento Revolucionario Túpac Amaru (MRTA) o del dogma democrático sostenido por los gobiernos de turno - sino desde las sub-versiones para "todos", desde la fe comunista, desde los sueños que serán vistos por los hijos, desde el creer que es posible un modo diferente de distribución del poder, desde la creencia posible de tener un lugar "junto al calor”. Lugar que a Bera Iznez, como mujer y ser humano se le había negado. 
Uno de los dogmas instalados y repetidos por los partidos comunistas peruanos tiene que ver con la concepción del rol de la mujer en la familia y el estado propuesto por Federico Engels. El filósofo alemán habla de una división primitiva del trabajo en el que el hombre del clan realizaba actividades que tenían que ver con el exterior: caza y pesca principalmente; mientras que las labores productivas de la mujer eran internas o domésticas como la fabricación de utensilios y las faenas en el huerto. Esta arcadia familiar y nómada se fracturó con la llegada del descubrimiento de metales como el cobre, estaño, bronce y hierro; es decir con la evolución de la técnica que proveyó al hombre de instrumentos de producción que a su vez impulsaron la agricultura y consecuentemente la esclavitud de otros hombres.

Los cambios tecnológicos transformaron radicalmente la concepción del trabajo doméstico. De ser considerado productivo pasó a ser, más bien, complementario o accesorio. Esta división del trabajo no se justifica en el orden biológico y sexual sino en el orden socio-laboral donde el hombre (patriarca) se afirma como propietario: de la tierra que la trabaja, de la fuerza de trabajo: primero la de él mismo, luego de los de su entorno inmediato, es decir la de su mujer y sus hijos; y finalmente de otros hombres y mujeres (los otros miembros del clan) a los que irá esclavizando.

Instalados en la familia patriarcal, entendemos con Engels que la opresión social de la mujer no radica en la diferencia sexual sino en el predominio de un desigual sistema económico. Panorama que lleva a Engels a concluir que el único modo de salir de la opresión que tiene la mujer es insertándose en el sistema económico y productivo de la "industria pública" (Engels, 2012, p. 98) en un sistema que tenga el respaldo jurídico que declara la igualdad de los sexos.

En esta configuración tecnológica y económica Beauvoir siguiendo a Engels ve la posible fusión entre socialismo y la "suerte de la mujer" estrechamente ligadas (1989, p. 98). El dogma socialista de Engels se instala en los medios de producción llegados con la modernidad, en el "maquinismo". La futura liberación de la mujer queda en manos de las acciones de la maquinaria política llamada dictadura "del proletariado" que impulsó la inclusión de la mujer en los medios de producción industrial.

Distanciándose del dogma tecnicista del comunismo científico Bera Iznes y con ella Ayala Leonardi, plantea que la lucha de liberación no se trata sólo de obtener un lugar jurídico y económico para la mujer. Lo que Bera Iznez demanda, y no solo para la mujer, sino para "todos" es un lugar en los afectos humanos. Ella lucha contra los afectos lívidos que en una sociedad patriarcal y espuria habían hecho de ella una mujer que no era a sí misma, donde la habían hecho imagen, para tirar o idolatrar cuando ella lo que quería es ser humana. Bera Iznez al principio de su noveno canto nos habla de la etapa culminante de un sistema segregacionista que expulsa a la imagen: "Después.../ me echaron a los caminos/ todos con las puertas cerradas,/ pues/ yo no era más yo/ sino/la imagen que hicieron de mí." (vv. 1-7). Versos con los cuales ella nos está conduciendo a un feminismo-comunista que va en el siguiente sentido: además de la imagen de mujer que construyeron de mí, soy biológica y potencialmente mujer.

El feminismo de Bera va más allá de la eterna lucha por ser deseo del otro. Apunta a una lucha por querer ser diferente a aquello que se cuenta por dado. Beauvoir señala que la mujer al declararse ser humano al igual que el hombre y negar su feminidad lo mismo que en otros terrenos el negar ser judío o negro, no es liberador sino una "huida inauténtica" (1989, p. 3) puesto que ninguna mujer puede "situarse por encima de su sexo." (1989, p. 3). Diríamos siguiendo el argumento de la pensadora francesa pero a través de la propuesta de 
Bera que nadie puede estar por sobre su singularidad orgánica. Lo diríamos convencidos que lo femenino o masculino o el ser mujer o el ser hombre no son sino formas que se imponen y performativizan, ideologizan, contra los cuales, desde el cuerpo, surge la utopía.

Ayala Leonardi, en ese sentido, no quiere limitarse a denunciar los actos de injusticia contra la mujer; pues, para ella el que el paciente de la injusticia sea hombre o mujer, pobre o rico, etc., es retórico y dogmático. En ella, la comprensión de lo jurídico y moral forma parte del discurso retórico. Por lo que para su personaje, Bera Iznez, no se trata de eludir la injusticia en su forma más fundamental: la segregación de lo biológicamente humano. Para ella, todos son(mos) dignos de afecto. 
Bibliografía citada

AGAMBEN, Giorgio. Lo abierto: el hombre y el animal; traducción de Flavia Costa y Edgardo Castro. Buenos Aires: Adriana Hidalgo, 2006.

ARELlANO CUEVA, Rolando y David BURGOS ABUGATTAS. Ciudad de los Reyes, de los Chávez, los Quispe... Lima: Epensa, Arellano Investigación de Marketing, 2004.

ARISTÓTELES. La Poética; traducción de Juan David García Bacca. México: Editores Mexicanos Unidos, 1989.

AYALA, Flor de María. Mujer de subamérica. Huancayo: Ediciones Caballo de fuego, 1988.

BADIOU, Alain. Lógicas de los mundos. El ser y el acontecimiento 2. Buenos Aires: Manantial, 2008.

BALLÓN AGUIRRE, Enrique. "Los Acrósticos De Vallejo." Escritos: Revista Del Centro De Ciencias Del Lenguaje 5 (1989): 75-97.

BARTHES, Roland. El grado cero de la escritura. México: Siglo Veintiuno Editores, 1983. BEAUVOIR, Simone de. El segundo sexo. Traducción de Pablo Palant. México: Siglo XX / Alianza Mexicana, 1989.

BURKE, Kenneth. Language as symbolic action: essays on life, literature, and method. California: University of California, 1966.

BUTLER, Judith. El Género en disputa: el feminismo y la subversión de la identidad. México: Paidós; UNAM, 2001.

DELEUZE, Gilles; Félix GUATTARI. Mil mesetas: capitalismo y esquizofrenia. traducción de José Vázquez Pérez y Umbelina Larraceleta. Valencia: Pre-Textos, 2010.

Diccionario soviético de filosofía. Ediciones Pueblos Unidos, Montevideo 1965. En línea. http://www.filosofia.org/enc/ros/comunis.htm

DERRIDA, Jacques. Fuerza de ley: el fundamento mistico de la autoridad; traducción de Adolfo Barberá y Patricio Peñalver Gómez. Madrid: Tecnos, 2008.

DIEZ-CANSECO, José (Perú, 1904-1949). "El trompo" en Estampas mulatas. 1938. En línea http://haravicus.blogspot.mx/2008/07/el-trompo-javier-diez-canseco-cuento.html.

ENGELS, Friedrich, 1820-1895. El origen de la familia, la propiedad privada y el Estado. Biblioteca Virtual Espartaco/ Archivo Marx. www.marxists.org. 2000, 2012.

FOUCAULT, Michel. La arqueologia del saber. 1970 Traducción de Aurelio Garzón del Camino. Buenos Aires: Siglo Veintiuno Editores Argentina, 2002.

KLARÉN, Peter F. “'El tiempo del miedo' (1980-2000), la violencia moderna y la larga duración en la historia peruana", en Anne Pérotin-Dumon (dir.). Historizar el pasado vivo en América Latina. 2007. http://etica.uahurtado.cl/historizarelpasadovivo/es_contenido.php. MANRIQUE, Nelson. El tiempo del miedo. La violencia política en el Perú 1980-1996. Fondo Editorial del Congreso del Perú, 2002.

MARIÁTEGUI, José Carlos. El artista y la época. Lima: Biblioteca Amauta. 1987.

MOI, Toril. Teoría literaria feminista. Traducción Amaia Barcená. Madrid: Cátedra, 1988. ROY, Fabienne van y C. Lizárraga. Te vas haciendo mujer. Bilbao: Desclée de Brouwer, 1984.

YATES, Pamela. Estado de miedo [videograbación]. [Madrid]: Morena Films: Documentales Fnac, 2007 
Anexo

Flor de María Ayala Leonardi

Mujer de Subamérica (1988)

Bera Iznez

(1986)

"pero, yo no quiero

que mi vida te sirva

para escribir una de

ésas tus cosas..."

1

Esto no tiene principio

¿sabes?

Apenas mi vida

anidaba en su carne

5

cuando los pájaros

de mal agüero

le dijeron:

"será mujer"

y al no poder deshacerse de mí

10

me ignoró simplemente

2

Un día, me desperté soñando:

un revoloteo de trenzas

se desprendía de mí

5

y volaba a las manos de mamá

para robarle sus caricias.

Pero,...

los sueños son sólo eso...

3

Algo que nunca pude entender

ni quise

el trompo zumbaba en mis manos

mejor que en cualquier otra

y era yo

el único soldado sobreviviente

en todas las batallas. 
¿Cuál es la diferencia?

No puedo reemplazar la imagen

10

ni la creciente debilidad

de la carne flaca.

4

Yo quería sentarme a su lado

y lenta, dulcemente

empezara a contarme las cosas

¿por qué no somos iguales?

5

Entonces...

me regaló

Te vas haciendo mujer

$\mathrm{y}$ entre la docta frialdad de unas páginas

10 encontré cuál era la diferencia.

Pero no lo que se debía hacer

para no vomitar

cuando te desvisten con la mirada.

¿Hay que correr siempre

15 para que no te toquen?

¿Qué es el deseo

dónde se esconde,

dónde reposa,

quién lo despierta...?

5

Yo tenía mi libro, después... otros más

pero ella nunca tuvo tiempo

sino

5

para perderse

entre la espuma del lavadero,

el polvo de la alfombra

y preparar la comida

a tiempo para ellos.

10 Por ellos,

ocupé mi lugar

junto a la escoba,

el detergente

y las ollas... 
Las otras

caminaban aéreas

con sus suaves sonrisas en ristre

yo nunca les hice nada.

Sin embargo,

un día,

vino una de ellas

me sacudió sus plumas

queriendo arrancarme

10

ni siquiera

algo que yo

había llegado a imaginar.

Gritó

15

que sus manos y las mías, su cuerpo y yo...

pero no necesito jurarte no estuve allí

Claro, esa onda no es para mí.

en el internado nadie me creyó...

7

Primero vino una

luego otra

y otra...

Todas creyendo

5

10 con los sueños recién florecidos

que era tiempo

para la repartición del botín

pero esta fruta

madura a la fuerza

construyó su propia fortaleza

en la ilusión de unos músculos cuadrados

guardando su cintura.

Mas, no todo era fácil, como antes,

15 ya no servían las almohadas

para trinchera

y no se podía huir

en un caballo de escoba

de sables sirvieron

20

las uñas

y de escudo

los dientes

extenuadas

huyeron Obediencia, 


\section{Castidad,}

recogiendo apresuradas

sus inútiles ropajes...

8

¿Por qué tuvieron

que señalarme precisamente

a mí

entre otras bien dispuestas

5

escogieron a esta pobre ardilla asustada?

No vi cuantos eran

se vistieron con la noche, saltaron las puertas, costuras y

botones.

Luché en vano

eran muchos brazos muchas bocas

y una sola desesperación

15 multiplicada por el asco.

Demasiado tarde, la ayuda llegó

demasiado tarde

hubiese preferido morir antes

20 a los seis, nueve o doce años

bajo los diarios golpes de mi padre

y la indiferencia de mamá

pero nunca me quiso nadie

ni siquiera la muerte.

9

Después...

me echaron a los caminos

todos con las puertas cerradas,

pues

5

yo no era más yo

sino

la imagen que hicieron de mi.

Tuve sed

bebí mis lágrimas

10 pasé hambre

no encontré una mano extendida.

Con el tiempo

curaron mis heridas 
mire hacia afuera

escurrí mi dolor y secó al sol.

Descubrí otra clase de padecimientos

también el origen,

la causa de la creciente división

y la lucha

también descubrí una palabra

mi palabra: PODER

10

Antes,

creía en el mal y el bien

cosas inconsistentes,

sin fuerza,

no existen por sí mismos

dependen del poder.

Poder ser rico,

ignorante,

hambriento,

10

soñador...

Poder luchar

por las creencias:

para todos

el pan fresco de cada día

junto al calor.

y un lugar

11

Poder pelear por los sueños

el mío

se repite constantemente ¿sabes?

Por fin amanece el día preciso

y empiezo a caminar

libres de hitos

avanzan todos los verdores, bajo mis pies

corren las arenas y las nieves.

10 Voy en medio de la multitud

y, a lo lejos,

los pinos arista nos ven pasar

Vamos todos cogidos de las manos

15

y el trabajo.

Ya nada es tuyo

ni mío

y todo,

todo es nuestro para siempre

desde el mar a las montañas 
Y nuestros hijos juegan como las ballenas libres, los visones libres

y cada tigre con su propia piel.

Tal vez, no despierte a mi sueño hecho realidad, sin embargo, no me importa sembrar y sonreír porque mis hijos o los hijos de mis hijos, verán este sueño por mí. 